\title{
Propuesta y modelos para la gestión estratégica de los centros urbanos desde la cooperación pública y privada
}

\section{Agustín Rovira Lara *}

\section{Introducción: ¿Una ciudad ideal sin centro urbano?}

En algunas conferencias en las que he participado recientemente planteaba a los asistentes la pregunta: ¿Se pueden gestionar los centros urbanos?; así pues, sirva también como provocación al lector esta otra pregunta: ¿Una ciudad ideal sin centro urbano? Frank Lloyd WriGHT (1867-1959) puede ser considerado como el arquitecto más importante y original de los Estados Unidos, uno de los creadores de la arquitectura y del diseño moderno. WRIGHT como urbanista fue un visionario que supo captar y comprender las profundas transformaciones en los hábitos de vida de la población americana y supo incorporarlos a su concepción de los espacios arquitectónicos. Su libro The Living City (La ciudad viviente), publicado en 1958, presentó una visión idealizada y profética de lo que se avecinaba.

Wright fue el primer arquitecto en comprender las consecuencias del uso masivo del automóvil para la sociedad urbana y planteó propuestas revolucionarias para integrarla en sus proyectos arquitectónicos. La ciudad viviente que concibió WRIGHT en los años veinte ya cuestiona el concepto de ciudad occidental porque el desarrollo urbano americano necesitaba de extensas zonas y el centro urbano tradicional estaba en proceso de descomposición, ya que no era capaz de asumir el papel de centralidad de un nuevo modelo de crecimiento. Lo que ocurría en esos años con la formación de la ciudad de Los Angeles se oponía al concepto que se tenía tanto del campo como de lo urbano. Su visión idílica era la de una comunidad sin fronteras geográficas y abierta, democrática y comunitaria, en consonancia con la naturaleza.

La Ciudad Viviente ${ }^{1}$ predijo la fuerte descentralización que se produciría gracias al uso generalizado del automóvil ${ }^{2}$ y que hoy puede compararse con las profecías de las ciudades futuristas de las modernas tecnologías de la comunicación que pueden alentar al abandono de centros y espacios urbanos frente al atractivo de vivir y trabajar en las periferias, en el campo o en los cada vez más urbanizados espacios alejados de los centros urbanos tradicionales.

Sin embargo, frente a esta concepción la ciudad que ha marcado muchos de los desarrollos urbanos del siglo xx que hoy se extienden por todo Occidente, en las ciudades europeas con raíces históricas, el corazón sigue latiendo en sus centros urbanos. Hoy existe un amplio consenso político y técnico para que los poderes públicos tomen conciencia de la necesidad de conservar y regenerar los centros urbanos, especialmente los centros históricos y los centros urbanos tradicionales. La Ciudad Viviente es precisamente la que sigue conservando y regenerando su centro urbano.

El uso de todo tipo de términos, que a veces se confunden o se intercambian sin mucha precisión, abarca toda la serie de los «re» para tratar de expresar la necesidad de conservar la vitalidad de los centros históricos: recuperación, rebabilitación, renovación, reconversión, reestructuración, revitalización, regenera- 
ción, a los que habría que añadir otros como: dinamización, modernización o competitividad de estos centros. Todos estos términos tratan de referirse a la necesidad de actuar tanto en el espacio físico como en el espacio social y económico del centro urbano. El debate, al fin, ya ha integrado el enfoque multidisciplinar tanto en el diagnóstico de los problemas del centro urbano como en las acciones que se presentan como soluciones. Definitivamente, el centro urbano necesita del concurso de lo público y de lo privado, del urbanismo y de la arquitectura, pero también de lo económico y de lo social.

La denominación de centro urbano ${ }^{3}$ es problemática y existe una amplia controversia sobre la misma. Las características materiales, formales y funcionales de la ciudad actual, que se caracteriza por el proceso imparable de la terciarización, están cada vez más unidas a un proceso de urbanización, difusas frente a la forma urbana compacta tradicional ${ }^{4}$.

El desarrollo de las nuevas formas de comercio periurbano han supuesto que la no-ciudad ${ }^{5}$ gane atractivo frente al centro ciudad, que debe ser reinventado y para ello es necesario recuperar el concepto y la función de centralidad. El concepto de centralidad urbana se ha abordado desde diversas perspectivas, pero tiene un triple componente: el sociológico, el morfológico y el económico. La mayor parte de las investigaciones basadas en trabajos de campo realizadas hasta el momento demuestran que «los caracteres de centralidad son percibidos por la mayoría de los ciudadanos pero necesitan de una conceptualización académica deducida de la práctica que sistematice estándares basados en la observación casuística de otras centralidades urbanas» ${ }^{6}$. La topología de los centros urbanos es muy diversa, y no es el objeto de este artículo, pero al menos se proponen los siguientes espacios conceptuales, y espacios percibidos de centralidad, que pueden configurarse como un todo o partes de un centro urbano y que son susceptibles de convertirse en espacios singulares para ser gestionados: Calles y/o ejes comerciales; zonas urbanas comerciales; cascos antiguos o centros históricos; centros urbanos tradicionales; centros urbanos sin carácter tradicional; centros ciudad y centros comerciales abiertos en el centro ciudad. Esta diversidad conceptual hay que relacionarla con una variedad de criterios y clasificaciones o tipologías de espacios comerciales (CASARES y ReBOlLo, 1996); (REYNOLS, 1992).

En el centro urbano confluye la dualidad ciudadano-comprador, y el ejercicio de la elección de los espacios de uso, consumo, compra y ocio se ve influido por los desplazamientos multipropósito, de manera que se busca la optimización del empleo del tiempo por parte de los ciudadanos y de los compradores en sus desplazamientos. La búsqueda de una «dimensión social del consumo», que todavía es minoritaria pero que busca escapar de Las formas comerciales agresivas y/o masificadas, las nuevas demandas sociales de más calidad de vida y, por lo tanto, también de calidad en los productos, servicios y también en los espacios sociales, urbanos, culturales, hacen necesario el debate y la pro- fundización en los modelos de gestión de los centros urbanos basados en ofrecer la calidad de los servicios del mismo al ciudadano.

La sociología urbana moderna ha señalado cuatro grandes funciones a la ciudad: el consumo, la producción, el intercambio y, por último, la regulación de las relaciones entre estas tres funciones ${ }^{7}$. Pero es precisamente el intercambio, como función que asegura el encuentro entre el consumo y la producción, el que deviene como principal elemento estructurante de la ciudad. El espacio urbano se puede considerar como el contenedor de todas las modalidades de intercambio y con sus infraestructuras facilita la fluidez del propio intercambio o lo dificulta. Pero hay un elemento fundamental sin el cual los intercambios no tendrían ningún sentido y es la presencia de los consumidores y/o usurarios que terminan por configurar un espacio social que confluye con un espacio físico y que, en último término, se trata de un espacio percibido. El centro urbano es, pues, un espacio físico, social y percibido, cuyo enfoque de gestión debe basarse desde esta triple perspectiva.

\section{La necesidad de un enfoque de gestión para el centro urbano}

El enfoque de gestión del centro urbano se sustenta en una serie de ideas fuerza o hipótesis de partida, todas ellas están avaladas por la experiencia y contrastadas en las aportaciones de profesionales, investigadores y observadores de la realidad urbana y socioeconómica.

La primera idea fuerza considera el centro urbano como un espacio relacional en el que concurren tres elementos: las personas, el espacio urbano como soporte físico y las actividades que se desarrollan en este espacio. Son tan importantes estos tres elementos como la compleja red de relaciones que se establece entre ellos. Las interrelaciones entre estos tres elementos son el campo de acción de la gestión y potenciar las sinergias de estas relaciones es una de sus funciones.

La segunda se refiere a que el centro urbano es, además de un espacio físico singular, un espacio bumano en el que la prioridad son las personas en sus diferentes roles (residentes, visitantes, compradores, turistas, peatones, comerciantes, etc.). Los usos del espacio por las personas deben orientar morfológica y funcionalmente cualquier actuación desde un enfoque de gestión.

La tercera idea fuerza se basa en considerar que el principal atractivo de un centro urbano es su diversidad y su diferenciación. 
Gestionar esa diversidad de usos, de oferta de servicios, de mix comercial, incluso de mezcla poblacional (multietnicidad, intergeneracional) es uno de los principales revulsivos para su regeneración. También el posicionamiento de un centro tiene que explotar los factores diferenciales del mismo frente a otras zonas urbanas y frente a otras ciudades que actúan en un mercado competitivo de localizaciones y de usos.

La cuarta se basa en reconocer que la actividad económica ba pasado a ser el motor de la revitalización del centro, y dentro de ella adquiere un papel relevante el comercio ${ }^{8}$ y también los servicios y el ocio. Todas estas ideas fuerza trascienden el urbanismo como actividad de programación de los usos del espacio del centro atendiendo únicamente a una dimensión física ajena a que son los usos y las funciones del espacio las que dan sentido a toda intervención. Los usos del espacio urbano tienen que ver con las decisiones humanas y sus funciones cambian con el desarrollo y la transformación de la ciudad que casi siempre responde a un difícil equilibrio entre el mercado y la planificación.

Pero indudablemente el centro urbano tiene una característica que lo diferencia de otros espacios de la ciudad: la centralidad que ya no es única ni excluyente y que comparte con otras áreas periféricas y con las que compite para atraer inversores, residentes y compradores o usuarios. La competencia entre lugares, la competencia centro-periferia exige que la puesta en valor de los espacios urbanos deban de ser procesos planificados y gestionados profesionalmente.

La necesidad de gestionar el centro urbano de la ciudad como un espacio singular radica también en que es en este espacio donde se encuentra la memoria histórica y el patrimonio cultural y arquitectónico más característico de la ciudad, el que constituye su principal atractivo para sus habitantes y para los visitantes. El centro urbano es donde suele ser más necesaria y compleja la intervención pública para recuperar el hábitat y transformarlo en un espacio de calidad, cómodo, accesible y al servicio de la ciudad en su conjunto. Y ésta es la verdadera clave de que justifica la aportación de recursos públicos: el centro es usado por toda la ciudad, el centro es un espacio vivido y percibido como tal por toda la ciudad.

\section{Una estrategia de marketing para posicionar el centro de la ciudad}

Tradicionalmente el marketing ha sido aplicado a la gestión empresarial. Pero en las últimas décadas se ha producido una extensión de su aplicación a otras áreas diferentes de la empresa. El marketing no empresarial, el marketing social, el marketing político o el marketing de ciudades son algunas de estas nuevas orientaciones (KOTLER, 2000).

El proceso de despoblación del centro, el deterioro de la edificación, la degradación del espacio urbano y de la calidad de vida, así como la competencia con otras áreas urbanas centrales y periféricas, que resultan también atractivas y son nuevos focos de centralidad, unido a las dificultades de la accesibilidad hacen necesario que la gestión de los centros urbanos tenga uno de sus principales apoyos en un enfoque de marketing.

El marketing de los centros urbanos no es más que una variante del marketing de ciudades y podría definirse como un «proceso de gestión de los recursos del centro cuyo objetivo es satisfacer la aceptación de los elementos de valor que éste incorpora, atendiendo a los diferentes públicos objetivos» (Gó. MEZ, 2000).

Se trata de una filosofía de gestión que deben compartir los que gestionan los recursos urbanísticos, culturales, ambientales, naturales, económicos y sociales del centro, pero que tiene tres limitaciones sustanciales:

La primera limitación radica en que de que el centro ya existe y no puede ser de nuevo creado, dispone pues de recursos dados y limitados, aunque pueden ser reinventados y pueden incorporarse nuevos recursos.

La segunda limitación es que la orientación al mercado es múltiple y diversa debiendo satisfacer una beterogeneidad de públicos objetivos (residentes, inversores, turistas, compradores, propietarios, etc.) y la segmentación de la oferta del centro - es difícil, pero necesaria.

Por último, la tercera limitación se refiere a la ausencia de un órgano de gestión identificado que asuma la responsabilidad de gestionar la organización que podemos denominar como centro urbano y que es al mismo tiempo el propio producto-servicio que se ofrece al mercado como una aglomeración de servicios tangibles e intangibles que el consumidor debe percibir como una oferta competitiva en su entorno frente a otras localizaciones.

El marketing empresarial cuenta con cuatro herramientas básicas en su ejecución: el producto, el precio, la distribución y la comunicación. ¿Es posible que el enfoque de marketing aplicado a un centro urbano utilice estos elementos? El diseño del producto-ciudad (GómEZ, 2000) o producto centro-urbano y la comunicación de ese producto son las dos herramientas que pueden resultar útiles en un enfoque de gestión.

El centro urbano puede ser concebido como un producto que hay que ofrecer a los públicos objetivos, y el diseño de ese producto debe hacerse atendiendo las necesidades de los 
posibles grupos de compradores del centro urbano. Para cualquier centro urbano atraer residentes es una forma de garantizar la renovación poblacional y la vitalidad social evitando el deterioro físico y la despoblación. La dificultad radica en definir el perfil del residente o del usuario-comprador que se necesita o se desea y posteriormente diseñar acciones de marketing adaptadas a esos públicos. Los turistas y los visitantes son en muchos casos un revulsivo para el desarrollo urbano, para el mantenimiento y conservación de los atractivos monumentales y arquitectónicos o para su puesta en valor de edificaciones y locales de ocio en el centro. En función del posicionamiento de cada ciudad y de los segmentos de turismo a los que dirigirse, las alternativas de ocio, cultura, patrimonio, servicios públicos y oferta comercial se convierten en los atributos del producto centro urbano (Kotler, Bowen y MaKens, 1997).

La creación de una imagen corporativa potente, atractiva, inclusiva y no excluyente, en la que basar la comunicación es la primera parte de una estrategia de comunicación. Pero no basta con crear la imagen, hay que usarla y promocionarla. Es insuficiente el uso de una imagen gráfica de marca genérica para el centro urbano si no se acompaña de una campaña de comunicación en la que se utilicen todas las herramientas del mix de comunicación, como la publicidad, la venta personal a través del personal de contacto con el ciudadano, el merchandising urbano, la promoción de ventas, las relaciones públicas; el marketing directo y relacional, la publicity, el patrocinio y el mecenazgo (REINARES y CALVO, 1999) y si esta actividad no se realiza de forma continua y planificada. Es precisamente la comunicación lo que principalmente han asumido las organizaciones comprometidas con el centro urbano, en especial las asociaciones de comerciantes que ya cuentan con experiencias de acciones de promoción realizadas de forma colectiva y que comenzaron con la creación de marcas corporativas, promociones de ventas conjuntas y acciones de fidelización de la clientela con el uso de tarjetas, así como con acciones de animación comercial y ciudadana?

El plan de marketing de un centro urbano es una herramienta básica en la gestión y se formula a partir de un proceso que cornienza en el análisis y diagnóstico de la situación, para seguir con la formulación de los objetivos estratégicos, las opciones estratégicas y los planes de actuación (SAINZ DE VICUÑA, 2000).

El análisis y diagnóstico de la situación se elabora a partir de la información disponible sobre el entorno, ya que se parte de la base de que el centro urbano compite frente o otras localizaciones de la ciudad, de la periferia y también frente a otras ciudades. En el análisis de la situación deben tenerse en cuenta todas las variables relevantes para diagnosticar la situación competitiva. Consta de dos partes diferenciadas, el análisis interno y el análisis externo. En el análisis interno se manejan indicadores demográficos, económicos, urbanísticos, sociales y culturales que permitan conocer el nivel y la calidad de vida de la ciudad, su capacidad de retener y atraer inversiones, turismo, residentes y actividades éconómicas. El análisis interno determina cuáles son los puntos fuertes y débiles en calidad de vida, transporte y accesibilidad, vivienda y edificación, seguridad, limpieza, servicios colectivos, infraestructuras, atractivos culturales y turísticos, ocio.

$\mathrm{El}$ análisis externo considera los factores del entorno que son políticos, legales, económicos, socio-culturales, tecnológicos, institucionales y de la competencia que pueden afectar al desarrollo del centro urbano. De este análisis se obtienen las amenazas y oportunidades.

El análisis DAFO ${ }^{10}$, que hace el inventario de las oportunidades, amenazas, fortalezas y debilidades del centro urbano, es una base de partida para continuar con la definición de los objetivos y opciones estratégicas. Al final el plan de marketing incorpora una colección de programas de acción que afectan a la imagen, al posicionamiento, a los atractivos y a la comunicación del centro urbano.

La determinación de objetivos a alcanzar estará en consonancia con el análisis realizado y deben ser claros, alcanzables, realistas, compatibles y mensurables en el tiempo y en el espacio. El proceso de fijación de los objetivos debe ser participativo y consensuado, puesto que se trata de construir el futuro del centro urbano a partir de la corresponsabilidad y el compromiso entre todos los agentes que intervienen en el centro de la ciudad públicos y privados.

Por último, quisiera introducir una de las reflexiones más estimulantes para la gestión de un centro urbano que puede aportar el marketing de servicios al intentar aplicar el concepto de servucción al servicio que proporciona el centro urbano a toda la ciudad. Al igual que los centros comerciales, los centros urbanos pueden ser considerados en parte como un conjunto de ofertas comerciales complementarias $y / 0$ competitivas integradas en un entorno urbano y que ofrecen una gran variedad de productos $y / 0$ servicios en un espacio delimitado en el que se pretende crear un ambiente cómodo, agradable y de calidad. En un enfoque de marketing, el centro urbano deberá satisfacer las diversas necesidades del cliente y producirles beneficios y/o satisfacción.

Los beneficios que puede reportar un centro urbano a la ciudad deben producirse a partir de la libertad de elección entre una amplia variedad de productos, servicios y, por tanto, también de establecimientos, pudiendo satisfacer las necesidades de compra y/u ocio de un amplio espectro de consumidores y/o usuarios. Para ello el alcance real de esta posibilidad de elección se basa en la accesibilidad y en la conveniencia de realizar las compras o el uso de servicios de forma eficiente en condiciones de calidad y precio adecuadas. Obviamente no todos los consumidores acuden a un centro urbano por los mis- 
mos motivos, ni perciben sus ventajas y beneficios del mismo modo.

Para poder ofrecer estos beneficios a los consumidores se puede plantear como reto intelectual el diseño de un proceso de servucción del servicio de un centro urbano. Este sistema se basaría en los siguientes elementos (BERRY y PARASURAMAM, 1993):

El cliente, como consumidor y/o usuario de la oferta de servicios y establecimientos del centro urbano.

El soporte físico: Se trata del soporte material que es necesario para la producción del servicio, y del que se servirán o bien el personal de contacto, o bien el cliente, o bien a menudo los dos a la vez En un centro urbano el soporte físico está constituido por todos los elementos muebles o inmuebles que lo configuran. Pero además hay que incluir también el entorno constituido por todo lo que se encuentra alrededor de los instrumentos: se trata de la localización, de los edificios, del decorado y de la disposición en los que se efectúa la servucción.

El personal de contacto: Todas las personas que prestan los servicios (comerciales, turísticos, públicos, privados, profesionales, etc.), y cuyo trabajo requiere el contacto directo con los clientes y los usuarios.

El servicio, que es el resultado final de la interacción entre los tres elementos de base que son el cliente, el soporte físico y el personal de contacto.

El sistema de organización interna. Mientras que la parte visible de la prestación de un servicio son el soporte físico y el personal de contacto, estos elementos están condicionados por la organización interna en una empresa de servicios, la parte no visible para los clientes. Es aquí donde cobra todo su sentido el enfoque de «gestión de los centros urbanos» como si se tratara de centros comerciales abiertos, y en los que la gerencia sería la responsable de toda la organización en la prestación del servicio a los usuarios.

Los demás clientes son también un elemento fundamental en el proceso de servucción, y todavía más en servicios destinados al gran público, como el que aquí nos ocupa. No sólo se establecen relaciones entre el soporte físico o el personal de contacto y cada cliente individual, sino que se establecen también relaciones entre los clientes que están físicamente juntos en el mismo lugar y que pueden influir en la calidad del servicio prestado a otro cliente y en la satisfacción que saca de éste.

Todos estos elementos traban una compleja red de relaciones primarias, internas y de concomitancia que sería preciso estudiar. Una aproximación conceptual al concepto de calidad en el servicio de un centro urbano pasa por el desarrollo de un modelo que debería basarse al menos en los siguientes marcos conceptuales: el modelo explicativo de las relaciones entre el entorno físico y el comportamiento del consumidor; las teorías sobre localización de establecimientos comerciales y de ser- vicios y el proceso de elección del consumidor; la teoría sobre el posicionamiento y la imagen percibida por el consumidor; el modelo de competencia entre ciudades y la mercadotecnia aplicada a los lugares; los enfoques de la sociología urbana basados en la diferenciación entre espacio social, espacio físico y espacio percibido; las relaciones entre el comercio y la ciudad y el comportamiento del consumidor y la teoría de la servucción aplicada al servicio de un centro urbano que se gestiona de forma integrada para la búsqueda de la calidad.

\section{Una estrategia para la regeneración económica y social del centro basada en la mejora del diseño urbano y de la accesibilidad}

Las estrategias para la mejora de un centro urbano se orientan hacia la regeneración económica y social de este espacio urbano. El soporte físico es el punto de partida, tanto el espacio público como el privado, tanto la edificación para la residencia como los contenedores de vida social, económica y cultural. Pero el punto de llegada trasciende la mera adecuación física de la edificación y de los espacios públicos para medir su eficacia en la regeneración social y económica de los espacios más degradados y en la calidad y capacidad relacional de los espacios que aúnan funciones de centralidad y representación de la ciudad. La mejora del diseño urbano a través de actuaciones de «microurbanismo comercial» " y la mejora de la accesibilidad son las dos cuestiones en las que puede basarse una buena estrategia, aunque como no son los únicos merecen una consideración especial debido al protagonismo que han adquirido en los últimos años.

La mejora del diseño urbano es una de las tareas más complejas en la gestión del centro, ya que hay que actuar sobre un espacio ya existente en el que la anchura y trazado de las calles, la localización de las edificaciones, los espacios públicos y los elementos estructurantes del centro están dados de antemano, bien sea por un proceso planificado o por la configuración histórica no planificada. Los errores en el diseño urbano generan problemas en la movilidad peatonal y rodada, ruido y contaminación, zonas de marginalidad, escasez de espacios públicos. 
El tratamiento urbanístico de las zonas comerciales urbanas de un municipio es un elemento crítico para la atractividad de un centro urbano. Es necesario dar un tratamiento global y unitario a toda la zona comercial que refuerce su imagen y su comodidad para el usuario. Hay que facilitar la accesibilidad $y$ la circulación peatonal en las zonas urbanas comerciales de centro ciudad, dándoles prioridad sobre la circulación rodada.

La movilidad urbana se reivindica y pertenece ya al catálogo de derechos de la ciudadanía. Cada cual la entiende a su manera, sea la movilidad en coche, o la olvidada y originaria del hombre que es moverse a pie. El peatón y el coche se han convertido en enemigos y en aliados, una historia de amor y odio digna de un guión cinematográfico. Una movilidad respetuosa con el medio ambiente es la mejor garantía de la sustentabilidad de la ciudad.

Muy pocos ayuntamientos europeos se han atrevido con medidas como el cierre de los centros históricos al tráfico. La medida suele ser impopular. Pero unos creen que es necesaria y que a la larga sería reconocida por los ciudadanos como acertada. Dos son las razones fundamentales que se esgrimen para pedir la prohibición: la preservación de los conjuntos arquitectónicos de carácter monumental y que se deterioran por las emisiones contaminantes y las vibraciones; y la otra es que, desde finales del siglo xvin, la urbanización de la ciudad se ha realizado de forma anárquica, con calles estrechas y sinuosas, con barrios densamente edificados y no pensados para la circulación de vehículos. La ciudad europea está generalmente inadaptada para acoger al vehículo en su centro histórico.

Para los expertos cualquier medida de prohibición, aunque necesaria, debe plantearse con precauciones para no transformar los centros históricos en islas que quedarían desiertas por su inaccesibilidad. La solución está en el diseño de una red de aparcamientos subterráneos y en superficie que sea capaz de acoger a los vehículos que pretenden acceder al centro. La localización, distribución y accesibilidad y gestión de estos aparcamientos es uno de los aspectos más polémicos y actuales de la gestión de los centros urbanos. El reto es gestionar bien el supuesto derecho o necesidad de los urbanitas a utilizar el coche en el centro urbano, para acceder al mismo y/o para circular por él.

Los cierres al tráfico indiscriminados de los centros urbanos si no van acompañados de medidas complementarias producen la expulsión de la actividad económica, especialmente del comercio, la desertización de zonas terciarias que pueden convertirse en guetos y lugares de marginalidad debido a la desvalorización del suelo y de los locales. En último término, las medidas prohibicionistas trasladan a otras zonas de la ciudad el caos circulatorio.

La mejora de la accesibilidad es una condición necesaria para la regeneración económica y social de los centros urbanos. La adecuada accesibilidad de un centro urbano constituye una de las claves para su competitividad frente a los centros comerciales periféricos, cuyo éxito se basa en gran medida en la oferta de facilidades de acceso y aparcamiento. Por accesibilidad se «entiende la variedad de facilidades o servicios disponibles para alcanzar una zona» ${ }^{12}$. El acceso a una zona o a una localización concreta se evalúa en función del tiempo empleado en el viaje, la distancia recorrida en el trayecto y el coste del mismo ${ }^{13}$. En el caso de un centro urbano, aunque la accesibilidad teórica puede ser elevada desde cualquier punto de su entorno por la disponibilidad de medios de transporte disponibles (autobús urbano, taxi, tranvía, vehículo privado, metro, peatonal), el acceso real puede no serlo, debido a la congestión (EzQuiAGA, 1999). Para evaluar la situación real del centro urbano en relación a la accesibilidad y el acceso es necesario considerar las diferencias entre el acceso real: medido por la duración real de los viajes desde diversos puntos y con diversos medios y en diversos horarios y días; el acceso subjetivo o acceso percibido: medido por el tiempo subjetivo que se deduce de las opiniones de los usuarios según los diversos medios empleados, y el acceso a los medios de transporte: medido por la localización de las facilidades e infraestructuras de transporte disponibles y que tienen que ver con la proximidad al domicilio del usuario y con la proximidad a sus destinos, al igual que con aspectos como la frecuencia y horarios del transporte.

Una de las decisiones más polémicas que deben tomarse en un centro urbano hace referencia a la peatonalización del mismo; en particular, pueden señalarse tres posibles tipos de actuaciones. La primera es la coexistencia del tráfico peatonal $y$ rodado. Es adecuada en aquellas calles o ejes comerciales que pertenecen a la red viaria básica del municipio y que, en consecuencia, no pueden cerrarse al tráfico. En este caso las medidas específicas para conseguir dar prioridad a la circulación peatonal consisten en ampliar la anchura de las aceras, reducción del número de carriles de circulación o/y de aparcamiento y cambios en la señalización y semaforización. La segunda es la peatonalización flexible que permite que la circulación peatonal sea la prioridad. No obstante, se permite la circulación regulada en ciertas circunstancias, bien sea mediante regulación horaria, o por tipo de vehículo (se autoriza el paso de autobuses, taxis, servicios públicos, etc.) o regulación según el tipo de usuario (residentes, carga y descarga, etc.). Es en este tipo de actuaciones donde debe haber una mayor intervención urbanística, debido a que el pavimento debe adecuarse tanto a la circulación rodada como a la peatonal. De cualquier modo, es conveniente unificar la calzada y las aceras, suprimiendo los bordillos y segregando la zona de circulación peatonal de la destinada a la eventual circulación de vehículos mediante elementos de mobiliario urbano o mediante el empleo de materiales diferenciados en el pavimento. La tercera opción es la peatonalización total sin que se permita el acceso de vehículos. Actuación reservada a ciertas zonas puntuales de cascos históricos, plazas, pasajes o travesías. 
Además de la accesibilidad, la mejora del diseño urbano es otra de las estrategias para la regeneración económica y social del centro. Es posible establecer una serie de principios elementales y generalmente aceptados sobre el tratamiento de los centros urbanos con objeto de aumentar la atractividad de su zona comercial, que es la que genera mayor afluencia de usuarios y que es la que percibe y usa toda la ciudad, por lo que la calidad relacional de sus espacios públicos y privados aplicados a las zonas comerciales son los siguientes:

El diseño y distribución del mix comercial. Los principales comercios, o «locomotoras», deberán situarse en los extremos de la zona comercial para maximizar el volumen de circulación peatonal y, de esta forma, crear un ambiente comercial atractivo. Además de una oferta comercial adecuada, deberá incluir un mix equilibrado de servicios, ocio, restauración ${ }^{14}$.

El diseño del paisaje urbano a partir de un tratamiento integral, simple y consistente, de la zona comercial ayuda a crear una atmósfera atractiva y confortable para la circulación peatonal. Los conceptos simples ejecutados con materiales de calidad dan los mejores resultados tanto desde el punto de vista estético como de mantenimiento. El diseño de la calle debe enfatizar la continuidad del espacio, resaltando su potencial para diferentes usos y actividades.

El correcto dimensionado y diseño de las aceras es un elemento clave para lograr que una zona comercial sea atractiva para el visitante. Una anchura mínima de aceras de 4 a 5 metros en la zona comercial principal permite establecer una primera zona de 3 metros junto a los escaparates destinada a la circulación peatonal, y una banda lateral de 1,5 metros junto al bordillo, para mobiliario urbano y señalética.

Una pavimentación singular, que diferencie la zona comercial del resto de calles de la ciudad, puede tener un impacto positivo en la creación de un ambiente acogedor. Además de atractivo, el pavimento debe ser cómodo para todo tipo de visitantes y en cualquier tipo de condición climatológica. Debe cuidarse especialmente la supresión de barreras arquitectónicas y el rebaje de bordillos en los vados y pasos de peatones.

Una selección adecuada de los diferentes elementos de mobiliario urbano (farolas, bancos, papeleras, teléfonos públicos, kioscos, marquesinas de paradas de autobús, etc.) puede incidir positivamente en la atractividad de un centro urbano. La colocación de dichos elementos, así como la localización de terrazas y similares, no debe dificultar la continuidad del movimiento peatonal.

El tratamiento verde del medio urbano mediante la incorporación de árboles en las zonas de las aceras próximas al bordillo es una medida adicional para segregar la circulación peatonal del tráfico rodado. Proporciona sombra y crea un ambiente atractivo que invita al paseo. El tratamiento de los jardines y espacios verdes supone otra de las bases de la convivencialidad del centro urbano.
La señalética es otro elemento básico para crear una zona comercial atractiva y facilitar la circulación peatonal tanto la señalización informativa, como las relativas a la regulación de la circulación de vehículos y los rótulos de los comercios. No obstante, el diseño y localización de postes y señales debe tener en cuenta que su impacto visual no sea excesivo y que no dificulten el tránsito peatonal.

La iluminación del espacio público. Crear una iluminación permanente que proporcione un entorno seguro y acogedor, la altura de las farolas situadas en las zonas peatonales no supere los 3,5 metros. En las intersecciones, y con objeto de iluminar mejor las calzadas de circulación de vehículos, pueden alternarse con farolas de mayor altura.

\section{Los modelos y las fórmulas de gestión}

Las experiencias de gestión de los centros urbanos son muy heterogéneas en nuestro país. Muy pocas ciudades han afrontado estratégicamente la gestión integrada de su centro urbano y menos desde una colaboración leal y eficaz entre el sector público y el sector privado. Muchas ciudades han puesto en marcha todo tipo de proyectos dirigidos a recuperar, rehabilitar y revitalizar sus centros históricos y en ese objetivo han contado con la colaboración y también la crítica de los colectivos afectados. La iniciativa casi siempre se ha emprendido desde las Corporaciones Locales y las Comunidades Autónomas ante una mayor conciencia ciudadana o ante la reivindicación de colectivos empresariales y sociales.

Los diferentes agentes públicos y privados que intervienen en la dinamización de los centros urbanos carecen de experiencia en la coordinación de sus políticas y los instrumentos de gestión son propios de cada una de las organizaciones. En el reparto de funciones y tareas hay solapamientos y la competencia por ejercer el liderazgo, el protagonismo y la reivindicación hacen frecuentemente fracasar los proyectos y producen resultados parciales.

Existe un amplio consenso, en el que se coincide en todos los foros profesionales, respecto de la necesidad y urgencia de un enfoque de gestión integrado para los diferentes procesos urbanísticos, sociales y económicos que concurren en el centro urbano. Se destaca el déficit gerencial o la carencia institucional como uno de los problemas ineludibles para afrontar por parte de los agentes implicados un proceso de recuperación y dinamización de los centros urbanos ${ }^{15}$. El modelo de gestión de los centros urbanos debe ser integrador, flexible, adaptado a las características de cada ciudad y de cada entorno institucional 
en el que se implante. No parece viable la traslación de una experiencia sin la correspondiente adaptación a la realidad física, social, económica e institucional de cada centro histórico. El benchmarketing resulta aquí una técnica útil y escasamente utilizada.

Hay que examinar primero los instrumentos que jurídicamente disponen las Administraciones Locales como fórmulas de gestión para abordar el centro urbano. La Ley Básica de Régimen Local (LBRL) define los servicios públicos locales y enumera las formas de gestionarlos en su artículo 85 . Se recoge un concepto muy amplio de lo que se entiende como servicio público local ${ }^{16}$ refiriéndose a que es todo aquello que tiende a la consecución de los fines de competencia de las entidades locales. Distingue entre servicios propios que se prestan en el ejercicio de las competencias atribuidas en este concepto por la Ley y servicios delegados por el Estado o las Comunidades Autónomas e incluso se incorpora también la idea de servicios en colaboración o de servicios complementarios ${ }^{17}$ de actividades propias de otras Administraciones.

Las modalidades de gestión indirecta no se aplican a todos los servicios públicos y actividades económicas locales. Quedan siempre excluidas las que supongan el ejercicio de la autoridad que deben prestarse de forma directa sin órgano especial. Pero para aquellos servicios que puedan ser explotados económicamente se establecen las siguientes modalidades que podrían trasladarse a la gestión de un centro urbano, como: la concesión, la gestión interesada, el consorcio, el arrendamiento o la contratación de empresas mixtas.

Mediante la concesión la Entidad Local cede en determinadas condiciones la gestión y explotación de una actividad de su competencia, a una persona física o jurídica que asume el riesgo económico de la misma. La concesión supone transferir los riesgos económicos de la explotación al concesionario, que es $\in \mathrm{l}$ que percibe de los usuarios las tarifas autorizadas y que son su fuente de ingresos. La fórmula se ha utilizado para la explotación de mercados municipales y aparcamientos públicos, pero resulta del todo improbable en la gestión de un centro urbano.

La gestión interesada se introduce en la Ley Reguladora de Bases de Régimen Local y es una fórmula de gestión mixta que tiene su origen en un contrato cuyo contenido debe fijar si es la Administración quien explota el servicio con el concurso de un gestor a quien se le garantizan unos beneficios mínimos, o es el gestor el que explota el servicio a cambio de aportar a la Administración unos ingresos. En todo caso, el enfoque de esta fórmula es la colaboración pública y privada expresa asumiendo los resultados de la explotación del servicio de forma conjunta y en la proporción que se establece en el contrato. Esta fórmula ofrece posibilidades pero de elevado riesgo para enfocar la gestión de un centro urbano.
El concierto ${ }^{18}$ permite que una Entidad Local pueda acordar con otras Entidades públicas o privadas radicadas en su territorio sin crear una nueva persona jurídica. Algunos servicios públicos se gestionan mediante el concierto entre Administraciones de distinto ámbito territorial. La fórmula es inédita y podría funcionar en el caso de la gestión de los centros urbanos en la que el impulso autonómico es esencial y se debe contar con la Administración Local de la ciudad.

El arrendamiento del servicio permite la explotación del mismo en las instalaciones de la Corporación Local por lo que se trata de un arrendamiento de instalación. Pero también puede darse la contratación de los servicios personales de una empresa privada que presta el servicio en interés de la Corporación; entonces la fórmula es el arrendamiento de servicios personales. El arrendamiento de servicios no supone nunca la delegación de potestades públicas y el arrendatario se limita a prestar el servicio mediante precio o contraprestación por el trabajo, cobrando el Municipio las tasas correspondientes ${ }^{19}$.

Las empresas y cooperativas mixtas ${ }^{20}$ cuyo capital social pertenece sólo parcialmente a la entidad local son otra forma de gestión. En este caso el acuerdo constitutivo de la Sociedad mercantil o Cooperativa en la que va a participar la Entidad Local puede establecer especificaciones internas, estructurales y funcionales que exceptúen la legislación societaria aplicable sin perjuicio de terceros. Se trata de una figura flexible en la que los particulares pueden integrarse de distintas formas: Participando en una sociedad ${ }^{21}$ ya constituida mediante la adquisición de acciones o participaciones en proporción suficiente para compartir la gestión social o a través de un Convenio con la Empresa ya existente recogiendo un Estatuto por el que se regirá en el futuro. También se puede constituir una nueva sociedad con la participación de la Entidad Local y la aportación de capital privado mediante la suscripción pública de acciones o mediante la convocatoria de un concurso que la Entidad Local puede establecer para que se formulen propuestas respecto a cuál debe ser la fórmula de cooperación pública y privada fijando el modo en que se debe constituir el capital social y la reserva que pueda hacer la Entidad sobre la dirección de la Sociedad a crear y los posibles beneficios o pérdidas ${ }^{22}$.

Existen también las modalidades de gestión directa de los servicios que pueden prestar las Entidades Locales. Se trata de fórmulas de gestión asumidas por la propia Entidad Local o bien de forma descentralizada a través de sociedades mercantiles dependientes en exclusiva de la Entidad o de organismos autónomos locales ${ }^{23}$. Todos los servicios locales son susceptibles de gestión directa, pero los que supongan el ejercicio de la autoridad deben prestarse de esta manera. Las formas de gestión directa según la Ley de Bases de Régimen Local son cuatro: por la propia Entidad Local sin un órgano especial, mediante una organización especial, mediante un Organismo Autónomo Local o mediante una sociedad mercantil exclusiva. 
La gestión por la propia Entidad Local sin un órgano especial implica que es el propio personal de la Entidad el que presta el servicio dependiendo en sus actuaciones de los acuerdos y actós de los órganos de gobierno de la Corporación Local ${ }^{24}$. Esta modalidad no ofrece ninguna posibilidad de gestión público-privada, ya que son los empleados y funcionarios municipales los que prestan el servicio y son los órganos de gobierno de la corporación los que tienen todo el poder de decisión y gestión. La dirección técnica se encomienda a un jefe de servicio y la gestión ejecutiva la realiza una unidad administrativa. La financiación del servicio se incorpora como dotación al presupuesto municipal. Cabe la posibilidad de constituir Consejos Asesores más o menos operativos o Comisiones Mixtas que dependerán en su función y eficacia de la voluntad política.

La gestión directa del servicio mediante una organización especial puede aplicarse a cualquier tipo de servicio local, salvo los que impliquen ejercicio de autoridad y los que sean de naturaleza mercantil o industrial. Se constituye un Consejo de Administración y un Gerente ${ }^{25}$. El Consejo es el que asume la gestión del servicio y sus acuerdos son recurribles ante la Corporación y los de ésta no se pueden recurrir ante los Tribunales. El presupuesto de la organización especial se integra en el presupuesto municipal en una sección presupuestaria específica y se lleva una contabilidad especial.

La gestión directa mediante un Organismo Autónomo Local supone que la Corporación Local es el titular del servicio, pero descentraliza su organización y crea un ente con personalidad jurídica pública que depende de ella y su presupuesto se incorpora al municipal ${ }^{26}$.

La gestión directa mediante una sociedad mercantil exclusiva implica que el capital social pertenezca íntegramente a la Corporación y el servicio se gestione a través de una empresa privada aunque de propiedad pública. La sociedad anónima o de responsabilidad limitada opera en el mercado de acuerdo con las leyes mercantiles, pero sus órganos de gobierno ${ }^{27}$ están conformados por el Pleno de la Corporación que actúa como Junta General, el Consejo de Administración y la Gerencia. Los Estatutos recogen las competencias de cada uno de los órganos.

Cabe también destacar dos fórmulas que pueden servir para iniciar un camino de colaboración publica y privada enfocado a la gestión integral de un centro urbano. Los Consorcios de promoción o de gestión, que se constituyen por asociación de distintas Administraciones Públicas tanto locales como de otro ámbito, y los Patronatos Municipales, que se han creado para la promoción turística y comercial de la ciudad que integran agentes públicos y privados con el objetivo de dinamizar los atractivos de la ciudad, aunque su actividad se reduce a la realización de actividades de información, animación y promoción. La creación de Fundaciones en las que se integran como socios las Administraciones Públicas y las entidades privadas asocia- tivas son una de las formas jurídicas más adecuadas, ya que se trata de entidades sin ánimo de lucro, pero que pueden crear sociedades para explotación de determinadas actividades económicas.

Los Convenios entre Administraciones Públicas Local y Autonómica para la creación de Oficinas o Agencias de Rebabilitación del Centro Urbano son otra de las fórmulas utilizadas para gestionar programas de renovación urbana de los centros urbanos, especialmente en centros históricos. Ante la expulsión de la función residencial y la degradación física de ciertos barrios de los centros urbanos, las Administraciones Públicas han desarrollado instrumentos de intervención dirigidos a rehabilitar y renovar el patrimonio inmobiliario y los espacios públicos, así como las infraestructuras de servicios dotacionales. El catálogo de intervenciones va desde intervenciones públicas directas en las zonas más degradadas con baja calidad arquitectónica y constructiva en las edificaciones ${ }^{28} \mathrm{o}$ en la rehabilitación del patrimonio monumental hasta actuaciones privadas aisladas o integradas que casi siempre se producen en espacios significativos de la ciudad de fuerte centralidad, con buena accesibilidad, con elevada calidad del hábitat residencial o en zonas de actividad económica y comercial. El resultado de estas actuaciones ha permitido que edificios singulares se dediquen a hoteles, cafeterías, edificios de viviendas, locales de negocio y centros o galerías comerciales, cines, teatros y locales de ocio, revitalizando la zona como consecuencia de las actuaciones públicas de la propia iniciativa privada. Este tipo de actuaciones ha generado experiencias de colaboración pública y privada que se han concretado en sociedades mercantiles de capital mixto para la rehabilitación del centro histórico y en programas de incentivos a la rebabilitación privada contenidos en normas de ámbito estatal y autonómico.

La gestión del centro urbano debe implicar a los propietarios de inmuebles, especialmente cuando se trata de inmuebles situados en lugares estratégicos del mismo. La regeneración del centro pasa por dinamizar áreas degradadas y por reinventar las funciones de ciertos inmuebles que permanecen vacíos o degradados al margen de la dinámica económica del centro. El proceso de regeneración conduce a la revalorización de ciertos espacios donde se localizan propiedades inmuebles que aumentan de valor.

Los facility manager o gerentes de recursos inmobiliarios de entidades y corporaciones pueden inspirar alguna de las funciones primordiales de la gestión de un centro urbano que es la de actuar como facility manager del patrimonio municipal y también de la activación del patrimonio inmobiliario privado, en especial de los locales para actividades económicas, de los edificios desocupados y de los solares.

Una de las figuras más prometedoras, aunque todavía poco utilizada, es la reciente creación del agente urbanizador a través 
de la Ley Reguladora de la Actividad Urbanística de la Comunidad Valenciana, que permite que un agente o promotor sea designado por la Administración como agente urbanizador de un área al que le otorga la capacidad de formular un proyecto de reparcelación. La empresa inmobiliaria que se convierte en agente urbanizador realiza la reparcelación frente al procedimiento siempre lento y conflictivo de la expropiación. Mientras que en los procedimientos de expropiación, el protagonismo lo toma la Administración Pública y su brazo burocrático-político, en la reparcelación se trata no de eliminar al propietario, sino de redistribuir la propiedad de forma que los propietarios reciban el valor equivalente a sus derechos tanto en propiedades o en valor económico equivalente, creando un nuevo reparto de la propiedad que posibilite la intervención. Hasta el momento la experiencia se ha desarrollado al margen de los centros históricos, pero es todo un reto aplicarlo a operaciones de remodelación de espacios en los centros históricos ${ }^{29}$. La clave de esta figura radica en que es posible que un agente urbanizador intervenga en una zona sin disponer de ninguna propiedad en el área en la que va a intervenir y que gestione un proceso de urbanización o rehabilitación remunerándoles en base al aprovechamiento urbanístico que genere la propia operación.

Los modelos de gestión del centro urbano deben basarse en la colaboración entre la iniciativa privada y la pública, a través de órganos de planificación, de gestión o de negociación: Comisiones mixtas ${ }^{30}$, Consorcios de promoción ${ }^{31}$, Consejos para la promoción económica y comercial, o figuras de gestión indirecta, como prevé la LBRL. Cualquier forma de concertación pública-privada es válida, al menos en un primer momento, en las tareas de diagnóstico de los problemas y de la formulación de las soluciones. En una segunda fase es necesaria la colaboración para fórmulas de gestión operativas en las que hay que liberarse de la excesiva burocracia. Una fórmula que puede ser un revulsivo en nuestro país, si se adoptan los cambios legislativos necesarios, es la que en Estados Unidos se denomina «Business Improvement District» (BID) ${ }^{32}$. Se trata de organizaciones privadas, sin ánimo de lucro que están legitimadas para imponer un recargo sobre los propietarios de locales comerciales en una área urbana bien delimitada a cambio de prestar ciertos servicios que principalmente se concretan en la seguridad, la limpieza y mantenimiento, la animación y la promoción de la zona. La legislación de los EEUU ha potenciado los BID's como fórmulas de gestión público-privada para áreas comerciales y de servicios. La idea es que la mejora de los servicios de una zona redunda en una revalorización de los activos, suben los alquileres y el valor de los inmuebles. Por eso es legítimo que se pague un recargo para financiar los servicios específicos de esa área. La implantación de un BID se hace por acuerdos mayoritarios de los afectados y obligan a todos. Ésta es la clave, imaginemos que nuestra legislación sobre comunidades de vecinos ${ }^{33}$ pudiera aplicarse a zonas urbanas gestionadas por comunidades de comerciantes y propietarios.
El centro urbano necesita de fórmulas que permitan su gestión integrada. No se trata de los enfoques de gestión tradicionales que pueden funcionar en una empresa o en una organización ya consolidada, aunque sus técnicas y sus instrumentos son de enorme utilidad. Se trata de una gestión creativa, de una gestión con un enfoque multidisciplinar. Tampoco se trata de resumir el problema de la gestión en la contratación de un gerente o un líder, más bien se trata de crear una estructura ligera, autónoma y flexible, pero integrada, controlada y participada por todas las partes interesadas en la ciudad, que cuente con apoyos y compromisos de financiación públicos, que incluya a todos y no excluya a nadie. La fórmula de gestión elegida tiene que servir para involucrar y comprometer a los agentes económicos y sociales (públicos y privados), tiene que ejercer un auténtico y leal liderazgo para proponer y asumir proyectos de consenso y compromiso. Se trata de que la gestión contribuya a buscar soluciones y no a generar nuevos problemas.

Una de las experiencias más interesantes y ejemplares de gestión del centro urbano, parte de la estrecha relación entre el comercio y la ciudad, se ha dado en la figura del llamado TCM, «Town center manager» en el Reino Unido. Se trata de una figura generalista impulsada desde la Administración local -cuya presencia es imprescindible para el éxito de un proyecto de gestión del espacio urbano- en cooperación con los distintos agentes que se han comprometido en la revitalización del centro urbano. El TCM es un coordinador, es una figura mixta pública-privada que actúa y gestiona un ámbito urbano bien delimitado, el centro, un barrio, un área urbana singular o toda la ciudad. No existe un estatuto jurídico único que dé sustento a la figura, ya que cada ciudad busca su solución organizativa y jurídica propia. El TCM actúa en los ámbitos del urbanismo, del medio ambiente urbano, seguridad y limpieza, promoción, marketing urbano, servicios sociales y culturales y ha surgido por el impulso de los comerciantes en un sentido amplio (comercio, empresas de servicios y hostelería) de un área urbana ${ }^{34}$.

La implantación progresiva de centros comerciales en la periferia de las ciudades liderados por una gran superficie comercial, como un hipermercado, un gran establecimiento o una gran superficie especializada, ha mostrado el conflicto centro ciudad-periferia; pero sobre todo ha puesto de relieve la eficacia de un modelo de gestión centralizado basado tanto en el uso común de un espacio, como en las ventajas de compartir una imagen conjunta y una larga serie de servicios tanto para el comerciante que se integra en el centro como los que conjuntamente se prestan al consumidor.

En la gestión de centros urbanos en España conviven actualmente tres niveles administrativos: la Administración General del Estado en cuanto al marco normativo de regulación de la propiedad y la actividad económica, la Administración de las Comunidades Autónomas en la regulación urbanística y la 
Administración Local. Este complejo panorama de competencias hace especialmente complicada la adopción de decisiones en las ciudades con espacios urbanos donde todas las Administraciones tienen algún tipo de regulación, intervención o gestión de algún proyecto. En España conviven tres generaciones de enfoques de gestión de centros urbanos:

La primera generación se da en aquellas ciudades con un deterioro físico de sus centros muy fuerte, que pierden población, y que disminuyen su atractivo y expulsan los negocios hacia las periferias. Estas ciudades tienen un marco legal municipal muy intervencionista y anticuado. La gestión no existe y las acciones de las organizaciones sociales y políticas consisten en reivindicar contribuyendo a la polémica social y política.

La segunda generación se da en las ciudades con un centro urbano en el que el deterioro físico se ha paralizado, la población ya no abandona el centro y se ha comenzado una tímida repoblación. También muchos negocios funcionan y la renovación urbana ha comenzado con un marco legal municipal más realista y flexible. La gestión de las organizaciones se dirige a la propuesta de proyectos, aunque no son capaces de gestionarlos todavía. Las organizaciones son más pro-activas, funcionan como verdaderos lobbys de presión y empiezan a hacer acciones de marketing y promoción. El protagonismo en esta fase es de los agentes económicos y sociales que influyen mucho en las acciones de los Ayuntamientos.

La tercera generación se da en las ciudades con un centro urbano muy atractivo, en el que se han implantado locomotoras comerciales y con un protagonismo muy decisivo de los pequeños comerciantes. Las intervenciones urbanas son frecuentes, tanto públicas como privadas. Hay equipamientos de calidad y un proceso de renovación urbana muy intensa. Las actuaciones urbanas se planifican y tratan de ser integradas. La gestión es ya estratégica, se dirige al largo plazo. Las organizaciones, tanto públicas como privadas, son muy activas y buscan la profesionalidad y la calidad en la gestión. El centro urbano compite con otros centros y áreas periféricas con éxito.

En España existen también tres modelos de profesionales vinculados con la gestión de los centros urbanos que quieren aproximarse a lo que podría denominarse la figura de gerente de centro urbano. Ninguno de ellos es todavía perfecto y sería necesario un nuevo marco legal para apoyar esta figura.

El primer modelo es el de un profesional, técnico de un Ayuntamiento, que se apoya en un equipo limitado de personas de dentro y fuera del Ayuntamiento. Es una forma adecuada para comenzar, aunque puede carecer de credibilidad entre el sector privado. Puede tener muchas dificultades si no hay financiación y si el concejal del que depende tiene poco peso político. Por el contrario, tiene la ventaja poder coordinar todas las actuaciones del Ayuntamiento en el centro. Una variante más avanzada es la creación de un instituto, un organismo autónomo o un patronato público encargado de esta finalidad. En general, el sector privado participa poco en este modelo. El mayor o rnenor protagonismo de las Juntas de Distrito del centro correspondiente al centro y su capacidad para gestionar es también un apéndice de este modelo.

El segundo modelo es el de un profesional, técnico de una Cámara de Comercio, o Institución Pública Empresarial, o mixta pública y privada. Es muy adecuado en ciudades pequeñas y medias que tienen una Cámara de Comercio local que funciona como un buen intermediario entre el sector privado y el sector público. Siempre es necesario el consenso y el compromiso tanto con el Ayuntamiento como con las Asociaciones de Comerciantes. En Cataluña se ha extendido la figura del dinamizador comercial con apoyo del Gobierno Catalán y en la Comunidad Valenciana se han creado la Agencias de Fomento de Iniciativas Comerciales (AFIC's).

El tercer modelo es el de un profesional, técnico de una Asociación de Comerciantes del Centro Urbano. Éste es el modelo más extendido, aunque carece de un marco legal adecuado en España. Funciona cuando la asociación es dinámica, representativa y está muy implantada en el corazón de la ciudad. Se trata de organizaciones profesionalizadas que dan servicio a toda la ciudad aunque en ocasiones los intereses son muy plurales y contrapuestos y faltan fuentes de financiación. En España estas experiencias y modelos se distribuyen por todo su territorio ${ }^{35}$.

\section{La actividad comercial y la gestión de los centros urbanos}

En febrero de 1999 se celebró en Málaga el Primer Congreso Europeo de Comercio y Ciudad para debatir de "Comercio y Ciudad, una nueva relación: Comprar y vivir en el siglo XXL». El Congreso concluyó con la llamada "Declaración de Málaga», que se ha convertido en una declaración de principios sobre cómo debe entenderse esta relación entre el comercio y la ciudad. La Declaración propone la idea de reconciliar la planificación urbana con la actividad comercial partiendo de la defensa de que la actividad económica comercial y de servicios es motor de la economía local y debe considerarse también como equipamiento para la comunidad y elemento que estructura el centro urbano como un espacio urbano vivo y atractivo para toda la ciudad. El documento reconoce que es posible y deseable la integración y compatibilidad de usos en los centros urbanos entre actividades económicas y comerciales, la residencia, el turismo, el ocio, el patrimonio y la cultura. El documento 
destaca la idea de gestión integrada de los centros urbanos mediante la creación de gerencias de centro ciudad que se sustenten en la participación, el compromiso y el consenso entre las Administraciones implicadas, los colectivos ciudadanos, las asociaciones de comerciantes y las Instituciones en un objetivo común, que es conseguir la renovación integrada del centro y también el liderazgo social de aquellos proyectos que de forma integrada pretenden transformar y modernizar la función de los centros urbanos. Esta Declaración ha tenido su continuidad en el reciente Congreso celebrado en la ciudad francesa de L'Ille, donde se ha vuelto ha reafirmar esta necesidad y se insta a la Unión Europea y a las Administraciones Públicas nacionales a actuar en este campo de forma decidida.

El comercio pone en contacto a las personas con las mercancías y con los servicios, es un espacio de convivencia y de intercambio tan importante como singular y necesario. El comercio no es sólo una actividad que pueda analizarse sin el asidero, ni la referencia a su localización concreta, al espacio en el que tienen lugar los intercambios. El «comercio bace ciudad», «el comercio da vida a la ciudad», no son sólo eslóganes, sino también ideas fuerza que orientan en la comprensión de la relación del comercio con la ciudad.

La ciudad ha evolucionado hacia la dispersión en su crecimiento. Se habla tanto del abandono de la ciudad como del retorno a la ciudad; del dilema centro-periferia, de la competencia entre ciudades y entre los atractivos, las ventajas y las desventajas de las distintas áreas urbanas. Hay un hecho importante que ha transfigurado la fisonomía de la relación del comercio con las ciudades: Los centros comerciales periféricos han crecido de forma muy importante en los últimos años en España.

Los grandes equipamientos territoriales con carácter comercial y/o complementariamente con oferta de servicios de ocio, personales o familiares, son focos de polaridad territorial (TARRA. GÓ, 1995) que generan flujos de usuarias y de compradores como consecuencia de su atractividad superando los límites convencionales de las jerarquías urbanas. De esto es de lo que hay que tomar conciencia, especialmente en las Administraciones Locales por parte de los planificadores y los urbanistas.

En definitiva, la ciudad se ha convertido en el espacio comercial idóneo y «las actividades del comercio en uno de los principales, o acaso el primer motor en la estructuración urbana» ${ }^{36}$. Pero esta relación comercio y ciudad ${ }^{37}$ está condicionada por una serie de elementos que complican y hacen de esta relación, aparentemente apacible y tradicional, una relación conflictiva, sobre todo por la influencia de los nuevos estilos de vida, hábitos de consumo y de compra. Veamos algunos ejemplos de este conflicto para la relación comercio y ciudad.

La segmentación de los mercados unida al crecimiento de la capacidad de consumo de las familias acrecienta la necesidad de concentrar ofertas homogéneas adaptadas a cada segmento que haga rentable la oferta por su tamaño y su capacidad de satisfacer al comprador. Esta segmentación conduce a una tensión en el centro urbano tradicional entre la diversidad de su oferta como atractivo y la búsqueda de la especialización como necesidad para competir, todo ello en un marco de decisiones individuales de localización y deslocalización que responden a lógicas empresariales ajenas al espacio urbano como un espacio integrado.

Los cambios sociales que afectan a los roles familiares han supuesto una auténtica revolución en los hábitos de compra tradicionales. La economía doméstica es cada vez más compartida y se tiende a concentrar los actos de compra y aumentar su volumen, alterándose las condiciones del comercio que en su localización demanda nuevos espacios comerciales adaptados. Los centros urbanos no pueden proporcionar estos espacios en un entorno competitivo y surgen centros alternativos al centro ciudad. La ciudad es cada vez más policéntrica, con centros a su vez alternativos y especializados ${ }^{38}$. Este fenómeno se refuerza ante la creciente movilidad que supone la incontenible motorización de la población con la posibilidad de acceder a centros alternativos.

El tiempo libre se ha convertido en un tiempo de uso y consumo de actividades lúdicas y de ocio. La compra es un acto lúdico y los servicios ligados al ocio adoptan formas y usos comerciales ${ }^{39}$. La mayor parte de los expertos sostiene que «el comercio como actividad económica puede favorecer el reequilibrio territorial y urbano» ${ }^{40}$. Una oferta comercial equilibrada y armónica en el territorio y en el espacio urbano es un factor de cohesión, de vertebración. Hay que tener siempre presente que el comercio es una actividad que genera centralidad y que es un factor fundamental en la creación de espacios urbanos convivenciales. Los grandes equipamientos y concentraciones de oferta comercial extienden su influencia y su impacto económico en un área que supera su estricta localización ${ }^{41} y$ esa influencia hay que tratar de maximizarla cuando sea positiva o minimizarla cuando rompa los equilibrios urbanos o territoriales. El funcionamiento del territorio y la movilidad no puede estar condicionada y atrapada por los emplazamientos comerciales, sino que éstos deben reforzar la cohesión del territorio. Por todo esto se debe apoyar a los centros comerciales tradicionales emplazados en centros urbanos de carácter histórico de forma que se asegure su pervivencia y su revitalización, manteniendo su función comercial y urbana, y fortaleciendo su papel de centralidad urbana y territorial. Esto es especialmente importante en los centros de articulación del sistema de ciudades, y en las ciudades que actúan como cabeceras de nivel regional, subregional, provincial, de demarcación territorial, de distrito territorial o de área funcional del territorio.

Las asociaciones de medianos y pequeños comerciantes deben tener un papel muy activo en este proceso. Nacieron para la autodefensa y la reivindicación, como fórmula de representar los intereses dispersos y a veces contrapuestos de los comerciantes especialmente frente a los poderes públicos. Al contrario que otros 
colectivos empresariales, están fuertemente atomizadas, escasamente organizadas y no actúan como lobbys eficaces. Se encuentran ante el dilema de organización territorial local con implantación en la zona donde desarrollan su actividad comercial frente a la organización sectorial más mediatizada en las luchas gremiales, politizada e insertada en otros ámbitos de organización que a menudo desdeñan la realidad local. Las actuaciones de las asociaciones han sido tradicionalmente de carácter reivindicativo y enfrentadas a las posiciones de otros comerciantes de mayor tamaño, de otros agentes sociales y políticos.

Es necesario revisar el concepto de asociación comercial ante los nuevos tiempos. Un nuevo concepto de asociación de comerciantes comprometida con la gestión comercial del espacio urbano sólo puede darse a partir de la fuerte implantación en el tejido local comercial y urbano, abierta a todas las tipologías comerciales. Que buscan compromisos tangibles de los asociados con acciones concretas y fuentes de financiación. Se trata de organizaciones volcadas en el servicio a los clientes y gestionadas profesionalmente con un perfil dialogante, negociador y fuertemente comprometido en el desarrollo de la ciudad. Que asumen actitudes pro-activas y no sólo reactivas o defensivas. Organizaciones que proponen ideas fuerza para la ciudad y que exhiben su responsabilidad social y su compromiso con la sociedad civil.

Cualquier aglomeración urbana que intente ser competitiva con otras en la periferia de la ciudad debe partir de un nivel de concentración comercial elevada en torno a una o varias calles principales o ejes comerciales bien definidos o sobre una trama urbana similar a una red o malla. Pueden darse combinaciones de ambas pero la concentración es condición necesaria aunque no suficiente para ejercer una función de centralidad y de atractividad comercial. El comercio da vida a la ciudad. Para que el comercio siga dando vida a las ciudades, las ciudades deben practicar políticas dirigidas a evitar la evasión del gasto y favorecer la proximidad de los equipamientos comerciales a los consumidores.

\section{Conclusión: el centro urbano en el marco competitivo de la ciudad habitable y sostenible}

El centro urbano es un espacio singular, es un escenario donde se desarrolla la acción humana. En ese escenario-espacio, es tan importante el contenido de la acción como los protagonistas de la misma. El espacio físico condiciona el desarrollo de la actividad humana y, al mismo tiempo, esa actividades y los usos de ese espacio identifican y caracterizan al centro urbano; la cualificación y la cuantificación de sus usos dependen de la relación que se establece entre el espacio con el ser humano y de esa relación surge un producto social. El centro histórico no es un espacio neutro y pasivo sobre el que se localizan objetos y se realizan actividades, sino que su forma y su percepción está en un continuo proceso de cambio, un proceso de cambio que deriva de la interacción espacio-actividad. El centro urbano es percibido a partir de su uso como producto social por parte de los ciudadanos. Todo esto nos conduce a admitir que el centro urbano es «un producto social» ${ }^{42}$, porque es la consecuencia de las características y el proceso de desarrollo de una determinada sociedad en un momento histórico concreto, porque es el producto de la iniciativa humana y expresa el proyecto propio de cada sociedad, porque es el resultado de la actividad y del trabajo de la sociedad de cada época y porque es un «objeto de consumo», si se me permite la expresión, con un precio, o lo que es lo mismo, con un coste para el usuario que puede optar entre distintas oportunidades y ofertas alternativas.

Si aceptamos que el centro histórico, como parte de la ciudad, como parte del territorio, es un producto social, cualquier actividad social contribuye a consolidar o modificar los rasgos característicos del centro urbano como producto social. El comercio es una de esas actividades que permiten configurar el centro urbano como espacio que resulte atractivo para los ciudadanos. Desde una perspectiva de intervención política, de gestión, de planificación y o de diseño de este espacio singular de la sociedad, contemplar la actividad comercial como motor de la revitalización es una exigencia en la mayor parte de estos espacios centrales de la ciudad. Pero el centro urbano es un producto social diferente a otros espacios.

La ciudad, tal como la entendemos a través de su evolución histórica, parece atravesar una profunda crisis a partir del crecimiento incontrolado de las periferias de las grandes metrópolis y la ocupación del territorio y del medio natural de forma indiscriminada. Una ciudad habitable y sostenible tiene que volver a recuperar el verdadero sentido de la ciudad y su centro urbano en sus dimensiones físicas y simbólicas, pero también en las funciones económicas y sociales es el corazón de la ciudad. El centro urbano está llamado a convertirse en un escenario para compartir el tiempo libre, para habitar, para cultivar el espíritu, para comprar, para compartir e intercambiar, para pasear y ver. Esto significa que el centro urbano debe recuperarse como espacio cultural, social y comercial. Esta vitalidad del centro urbano debe conciliarse con el respeto al medio ambiente y exige el control de los ruidos y la eliminación de todo tipo de contaminación, suciedad o deterioro. Frente a los espacios públicos y privados que dan soporte a una frenética actividad de intercambio deben preservarse espacios públicos de dimensión humana, a medida del «urbanista» que pasea tranquilo y vive la ciudad desde la contemplación y el goce. 
La búsqueda de ideas fuerza que sean capaces de movilizar recursos para revitalizar el centro de la ciudad es también la responsabilidad de los agentes sociales y, cómo no, de las asociaciones ciudadanas y entre ellas de las asociaciones de comerciantes. Los centros urbanos deberían relacionarse con atributos como:

- Un centro vivo, atractivo, cómodo, accesible, competitivo, activo (iniciativa económica, social, cultural), equilibrado (mix y complementariedad de usos), de calidad, al servicio de toda la ciudad y de su entorno.

- Un centro que extiende su influencia y sus beneficios para toda la ciudad. El centro es de toda la ciudad, lo usa toda la ciudad, representa e identifica a toda la ciudad. Es la memoria, la identidad y el patrimonio de toda la ciudad.

- Un centro que necesita un proyecto de consenso y participación. Hay que buscar el acuerdo, la suma, el consenso. El proyecto del centro urbano no puede ser un arma arrojadiza de unos contra otros, la polémica social o política no beneficia al centro y, sin embargo, es frecuente porque el centro es una caja de resonancia y un espacio de representación política y social que interesa a las partes en conflicto. A menudo el centro es utilizado y usado para otras finalidades en el debate ciudadano.

- Un centro que sea polo de atracción, que sea atractivo para los ciudadanos, para la innovación, para la cultura, para la actividad económica. El comercio aumenta el atractivo de los centros y favorece su uso ciudadano.

Las ciudades necesitan reinventar el centro urbano y dirigir también su mirada hacia su interior. El centro urbano es el centro de todas las miradas de la ciudad. Gestionar el centro no es sólo una idea sugerente, sino que puede convertirse en una verdadera idea fuerza que aglutine todos los esfuerzos dirigidos a revitalizarlo a partir de concebirlo como un «producto social», como un proyecto común que necesita gestión creativa, pero también, además de las ideas, organización y al menos tres recursos y/o capacidades: capacidad para involucrar convenciendo y motivando a nuevas conductas en los agentes y usuarios de centro; capacidad para proponer un proyecto y gestionarlo asumiendo riesgos; capacidad para buscar soluciones a los problemas separándose de «el pensamiento único» mediante la imaginación y la creatividad.
* Economista. Profesor Asociado del Departamento de Dirección de Empresas Juan José Renau de la Facultad de Economía de la Universidad de Valencia. Director del Curso de Gerentes de Centros Urbanos de la Universidad Miguel Hernández de Elche.

Director de la Oficina Pateco del Consejo de Cámaras de Comercio de la Comunidad Valenciana y la Conselleria de Industria y Comercio de la Generalitat Valenciana.

${ }^{1}$ La Ciudad Viviente de WRIGHT era una ciudad ideal donde «cada casa se ubicaba en un terreno propio, de una extensión mínima de un acre $\left(4.000 \mathrm{~m}^{2}\right)$, y cada edificio disponía de jardín. Las instalaciones municipales se disponían en medio de zonas verdes y se comunicaban a través de redes de calles que conducían a centros de ocio ubicados en lugares idilicos. Los centros urbanos desaparecen del todo y las oficinas se convierten en apartamentos. El sentido de la comunidad ya no viene determinado por el emplazamiento, sino que es escogido libremente, y ahora, los nuevos edificios dedicados a las artes y al ocio cumplen también La función de restablecer las relaciones sociales».

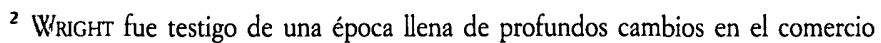
américano. De las tiendas de las pequeñas ciudades que florecían a principios del siglo hasta la aparición de los centros comerciales a los que se accedía en automóvil. WRIGHT amaba los coches como símbolo del progreso y la importancia de éste se refleja en toda su obra. Muchos de los edificios comerciales que concibió fueron proyectados pensando en el peatón o exclusivamente en las necesidades de los conductores de coches, pero siempre dentro de su concepto de Ciudad Viviente, en el que se respeta la naturaleza y el entorno.

${ }^{3}$ El concepto de management de centro urbano y la figura del gerente está directamente relacionada con la práctica anglosajona. El Town Centre Manager es la conceptualización de esta figura de la gestión dedicada a los centros urbanos.

${ }^{4}$ Ministerio de Economía y Hacienda; Secretaría de Estado de Comercio, Turismo y Pyme; Dirección General de Comercio Interior (1998), Gerentes de Centros Urbaros, Madrid, Colección Estudios. Este estudio fue elaborado por el Gabinete GAUDI y resulta especialmente interesante su análisis descriptivo de las políticas de dinamización comercial de los centros urbanos en la presentación de experiencias españolas (Santander, Zaragoza, Reus, Badalona, Tarragona, Gandía,
Móstoles, Córdoba, Granada y Málaga) y también europeas. Por otra parte, el estudio ha servido de base para la realización del Curso de Formación de «Gerentes de Centros Urbanos», ya que contiene una propuesta de contenidos mínimos para la formación de profesionales para el desarrollo de esta función.

${ }^{5}$ Ob. cit., p. 151.

${ }^{6}$ Ob. cit., p. 151.

' Puede verse: M. CASTELl (1974), La cuestión urbana, Madrid: Editorial Siglo XXI.

${ }^{8}$ El 6. ${ }^{\circ}$ Congreso Español de Centros Comerciales celebrado en A Coruña entre el 8 y el 10 de julio de 1998 se convocó bajo el tema «Crear comercio hace ciudad». En el Congreso se quiso constatar que el origen de la ciudad está en el mismo concepto de comercio como intercambio en su concepto más amplio. $\mathrm{Y}$ esta idea es la que sirve tanto para volver a confiar en el comercio como motor de la revitalización de los centros urbanos degradados o que han perdido sus funciones primigenias o para justificar la creación de centros comerciales en las periferias como motores de procesos de reurbanización y creación de ciudad. AECC (1999), 6. ${ }^{\circ}$ Congreso Español de Centros Comerciales, A Coruña, 8-10 de julio de 1998, Crear Comercio bace ciudad, Madrid: Evolución y convivencia:

${ }^{9}$ Pueden analizarse acciones promocionales realizadas por asociaciones en Bilbao, Málaga, Valencia, Gandía, etc.

${ }^{10} \mathrm{El}$ análisis DAFO es una de las herramientas para la planificación estratégica que mayor difusión ha alcanzado debido a la versatilidad y simplicidad. Corresponde a las iniciales de: Debilidades, Amenazas, Fortalezas y Oportunidades. The Boston Consulting Group fue el grupo consultor que ha asumido la autoria de esta herramienta metodológica que actualmente se aplica en un amplio abanico de estudios y análisis y que, aplicado a la planificación estratégica de territorios y ciudades, resulta un instrumento de gran eficacia por su capacidad analítica.

${ }^{11}$ El microurbanismo comercial adquiere todo su sentido en centros urbanos fuertemente terciarizados. El urbanismo comercial ha ido adquiriendo mayor cuerpo teórico y práctico a partir de las numerosas realizaciones en muchas ciudades, de la práctica profesional a menudo interdisciplinar. Marçal TARRAGó, desde la 
vertiente de economista urbanista y José María EzQUIAGA y Roger SánCHEZ como. urbanistas aquitectos han contribuido en gran manera a la consolidación de esta disciplina.

12 J. M. EzQuiaga (1998), Comercio y Planeamiento Urbano: Recomendaciones para la ordenación de las actividades comerciales en el planeamiento municipal, Ministerio de Economía y Hacienda, Secretaría de Estado de Comercio, Turismo y de la Pequeña y Mediana Empresa, Madrid: Dirección General de Comercio Interior, p. 31.

${ }^{13}$ J. M. EzQUiaGA, ob. cit., p. 31.

${ }^{14}$ Un buen modelo es el que combina comercio y ocio, especialmente hostelería en su más variada gama (desde el fast-food hasta los pequeños restaurantes tradicionales de calidad). Cualquier convivencia con el ocio nocturno resulta siempre conflictiva e imposible. El ruido y la ocupación indiscriminada de la vida pública es el principal motivo de expulsión de la población residente. Fórmulas como la creación de zonas acústicamente saturadas (Zas), junto a fórmulas de regulación de horarios, y condiciones estrictas de insonorización de los locales son necesarias. La ciudad no puede ser «usada» como un clínex. El principal motivo de residencia en una zona del centro de la ciudad es «la tranquilidad», la misma que lleva a la población a salir a las urbanizaciones de la periferia.

${ }^{15}$ La Dirección General de Comercio Interior de la Secretaría de Estado de Comercio, Turismo y de la Pequeña y Mediana Empresa integrada en el Ministerio de Economía encargó a Francisco Median del Gabinete GAUDI la realización de un estudio sobre la figura del Gerente de Centro Urbano y sus posibilidades de imbricación en la estructura institucional que opera en los centros urbanos de las ciudades españolas. El estudio se publicó con el título Gerentes de Centros Urbanos y se reseña en la bibliografía.

${ }^{16}$ El Capítulo III del Título II de la LBRL define las competencias municipales y el Capítulo II del Título III de la LBRL define las competencias provinciales.

${ }_{17}$ Artículo 28 de la LBRL. Los servicios de promoción económica local y empleo, educación, cultura, promoción de la mujer, vivienda, sanidad y protección del medio ambiente, también los atribuidos por normas sectoriales.

${ }^{18}$ Se le aplica el artículo 108 de la TRRL, y el régimen contenido en los artículos 43.2 , y 143 a 147 del RS, salvo cuando se trata de intervenciones tuteladas por la Administración General del Estado en que son suficientes los acuerdos de la Corporación.

${ }^{19}$ La diferencia entre el arrendamiento de servicios y la concesión como formas de gestión se establece en la Sentencia del Tribunal Supremo de 25 de noviembre de 1969 y en las Sentencias del mismo Tribunal de 17 de marzo de 1979 y de 8 de abril de 1980 .

${ }^{20}$ Se contemplan en el artículo 85.4.e) de la LBRL y los artículos 104 y 105 del TRRL desarrollan su tratamiento legal.

${ }^{21}$ El proceso de constitución de este tipo de sociedad se recoge en los artículos 104 y 105 del RS.

${ }^{22}$ Los aspectos relativos a las facultades de la Entidad Local en la adopción de los acuerdos de los órganos de gobierno y administración de la sociedad mixta, nombramiento del Gerente y de los miembros que representen a la Corporación, la disolución de la sociedad y de la reversión de los activos y pasivos a la Entidad Local, se recogen en los artículos 106 a 108 y 111 del RS.

${ }^{23}$ Artículo 85.3.a) y b) de la LRRL.

${ }^{24}$ Este tipo de modalidad se denomina gestión directa sin órgano especial o gestión directa simple o indiferenciada. Esta modalidad se aplica especialmente a los servicios monopolizados establecidos en el artículo 86.3 de la LBRL y artículo 100 de la TRRL. Necesariamente se gestionarán de esta forma los servicios que impliquen ejercicio de autoridad según el artículo 69.1 del RS.

${ }^{25} \mathrm{La}$ Corporación tiene potestad de autoorganización según los artículos 20.1.c) y 32.2 de la LBRL, pero en cuanto a la composición y nombramiento del Consejo y de su Presidente se estará a lo dispuesto en el artículo 73 del RS. El procedimiento de elección del Gerente y sus funciones se regulan en los artículos 74 y 75 del RS.

${ }^{26}$ Los supuestos en los que procede esta forma de gestión se recogen en los artículos 85 a 88 del RS. También se recoge en estos artículos el régimen económico, los Estatutos y órganos de gobierno y las facultades de tutela de la Corporación de la que depende. La STS de 22 de septiembre de 1995 estableció que el Ayuntamiento es responsable de las deudas del organismo autónomo.
${ }^{27}$ Artículos 92, 93 y 94 del RS.

${ }^{28}$ Este tipo de actuaciones han sido desarrolladas en muchas ciudades españolas. En Valencia, en 1992 se firmó el Convenio de Intervención Conjunta entre el Ayuntamiento y la Generalitat Valenciana que declaró el Área de Rehabilitación Urbana y creó un instrumento gestor de esa iniciativa que denominó Oficina Riva Ciutat Vella. El Plan Riva pretende ser no sólo un plan regulador y estructurador del territorio, de la urbanización y de la edificación, sino también un plan que contenga medidas de fomento de la revitalización y no sólo de la rehabilitación física. Las medidas son de carácter multidisciplinar y afectan al ámbito urbanístico, al social, a la vivienda, al comercial y al cultural. Puede verse: C. JIMÉNEZ (2000), ARCHIVAL.

29' Sólo la Comunidad Valenciana ha regulado la figura del Agente Urbanizador a partir de la aprobación de la Ley Reguladora de la Actividad Urbanística.

${ }^{30}$ Experiencia de la Comunidad Valenciana.

3. Lyon o Verona.

3: Tamiko YSA desarrolla ampliamente esta figura en uno de los artículos integrados en este número.

35 Ley de Propiedad Horizontal.

${ }^{34}$ En 1991 se constituyó la «Association for Town Centre Management» (ATCM), actualmente tiene más de 400 miembros que representan a 250 centros de urbanos en Gran Bretaña y que reúne profesionales de todos los ámbitos relacionados con los centros urbanos. En España, en 1999 impulsado desde la Oficina Pateco, se inició la primera experiencia formativa dirigida a preparar el perfil del gerente de centro urbano con un curso, patrocinado por la Dirección General de Comercio Interior del Ministerio de Economía y Hacienda; la Conselleria de Industria y Comercio de la Generalitat Valenciana y con la titulación universitaria de la Universidad Miguel Hernández. En el 2001 se celebrará ya su tercera edición con la participación del Consejo de Cámaras de Comercio y de la Confederación Valenciana de Comercio - COVACO—. También, fruto de esta actividad ha sido la creación de la Asociación Española de Gerencia de Centros Urbanos que ya está integrada en la ATCM.

3s Se podían presentar diversas categorías de experiencias o ejemplos de ciudades que han iniciado y están en un proceso ya avanzado de revitalización y gestión de sus centros urbanos. Así, tenemos en España ciudades con programas de recuperación urbana de sus centros históricos con resultados muy diferentes: León, Valladolid, Barcelona, Zaragoza, Valencia, Alicante, Murcia, etc. Ciudades que son Patrimonio de la Humanidad con programas de actuación singulares y ambiciosos: Santiago de Compostela, Segovia, Salamanca, Cuenca, Toledo, Ávila, Córdoba, Cáceres, etc. Ciudades que tienen centros urbanos muy activos y comerciales frente a la periferia y que han incorporado de distinta forma la figura del Gerente de Centro Urbano: Bilbao, que sería la ciudad pionera, Málaga, cuya gerente Carmen Criado es hoy la presidenta de la Asociación Española de Centros Urbanos, Teruel, Terrassa, etc. Ciudades con Programas de Actuación apoyados por la Unión Europea con Fondos Europeos que se aplican a zonas degradadas: Bilbao, Girona, Barcelona, Valencia, Madrid, Salamanca, Granada, Cádiz, etc. Ciudades y municipios, pequeños y grandes, de carácter turístico, en las que la recuperación de su centro urbano es un atractivo complementario a su especialización turística, especialmente en la costa mediterránea. Ciudades que han introducido un nuevo modelo de gestión basándose en la idea de los Centros Comenciales Abiertos, como Bilbao o Gandía; $\mathrm{Y}$, por último, ciudades que han funcionado como ejemplo de actuaciones en Urbanismo Comercial en distintas épocas, como Vitoria y Oviedo.

${ }^{36} \mathrm{M}$. TARRAGó, «Urbanismo Comercial. Respuestas de futuro para el binomio comercio y ciudad», Distribución y Consumo, núm. 2, Madrid: Mercasa.

${ }^{37}$ Ob. cit., pp. 15 y 16.

${ }^{38}$ Ob. cit., p. 18.

${ }^{39}$ Ob. cit., p. 17.

${ }^{40}$ Ésta es una las declaraciones básicas del PATECO, Plan de Acción Territorial aplicado a la Distribución Comercial en la Comunidad Valenciana.

${ }^{41}$ La elaboración de Isocronas permite determinar tanto las áreas de influencia teórica como real. Se trata de un instrumento imprescindible en la determinación de los impactos en el territorio de grandes equipamientos que suponen se basan en el atractivo de su influencia por el tamaño y la movilidad de los ciudadanos en el territorio.

${ }^{42}$ Puede verse J. EstÉbanez, R. MÉndeZ, p. 13. 
Berry, L., y Parasuraman, A. (1993), Marketing de Servicios. La calidad como meta. Gestión y Empresa, Barcelona: G. E. Parramón Ediciones.

Casares, J., y Rebollo, A. (1996), «Innovación y adaptación en distribución comercial. Ideas nuevas en odres viejos», Distribución y Consumo, núm. 27, abril-mayo.

CASTELL, M. (1974), La cuestión urbana, Madrid: Editorial Siglo XXI.

CHIAS, J. (1995), Marketing público. Por un Gobierno y una Administración al servicio del puiblico, Madrid: McGraw-Hill.

Cobra, M., y ZwarG, F. (1991), Marketing de servicios. Conceptos y estrategias, Bogotá (Colombia): McGraw-Hill.

DAvIs, G. (1992), «Positioning, image and the marketing of multiples retailers», The international Review of Retail, Distribution and Consumer Research, vol. 2, núm. 1, enero: 13-24.

Dawson, J. A., y LoRD, J. D. (1985), Shopping Centre Developpement: Policies and Prospcts, Dawson, J. A., y LoRD, J. D. (eds.), Kent.: Croom Helm.

Disllaert, B.; Arenteze, T.; Bierlaire, M.; Borges, A., y Timmermans, H. (1998), «Investigating consumers tendency to combine multiple shopping purposes an destinations», Journal of Marketing Research, núm. 35 (2), mayo: 177-188.

EZQUIAGA, J. M. (1998), Comercio y planeamiento urbano. Recomendaciones para la ordenación de las actividades comerciales en el planeamiento municipal, Madrid: Ministerio de Economía y Hacienda, Secretaría de Estado de Comercio, Turismo y de la Pequeña y Mediana Empresa, Dirección General de Comercio Interior.

Generalitat de Calalunya (1999), Guia d'identificació $i$ senyalització. Centres Comercials Oberts de Calalunya, Barcelona: Departament d'Industria, Comercs y Turisme.

Gómez, P. M. (2000), Marketing de ciudades en Marketing en sectores especificos, Aguirre M. S. Ediciones Pirámide: 265 a 299.

Hernández, M.; Munuera, J. L., y Ruiz Maya, S. (1995), «La estrategia de diferenciación en el comercio minorista», Información Comercial Española, núm. 739 , marzo.

Horovitz, J. (1990), La calidad en el servicio, Madrid: McGraw.Hill.

HuEte, L. M. (1994), «Factores que determinan la calidad en el servicio», Harvard Deusto Business Review, vol. 6, núm. 54: 76.87.

Kotler, P.; Bowen, J., y Makens, J. (1997), Mercadotecnia de localidades. Cómo atraer inversiones, industrias y turismo a ciudades, regiones, estados y países, México: Diana.

Kotler, P.; Cámara, D.; Grande, I., y Cruz, I. (2000), Dirección de Marketing, Madrid: Prentice Hall.

Martín Armario, E. (1993), Marketing, Barcelona: Ariel Economía.

Ministerio de Economía y Hacienda (1998), Gerentes de Centros Urbanos, Madrid: Colección Estudios, Secretaría de Estado de Comercio, Turismo y Pyme, Dirección General de Comercio Interior.
NIETo RiverA, A. (2000), «El marco jurídico del desarrollo local», Capítulo VII de Desarrollo Local: Manual de uso, Pérez Ramírez, B., y Carrillo Benito (coords.), Madrid: E. Esic-Federación Andaluza de Municipios y Provincias.

Parasuraman, A.; Zeithaml, V., y Berry, L. (1985), «A conceptual model of service quality and its implications for future research», Joumal of Marketing, vol. 49: 41-50

Pascual i Esteve, J. M. (1999), La estrategia de las ciudades. Los planes estratégicos como instrumento: metodos, técnicas y buenas prácticas, Barcelona: Diputació de Barcelona.

REFFATT, P. (1996), «La servucción o cómo producir un servicio de manera eficaz», Harvard-Deusto Marketing \& Ventas, núm. 13, marzo-abril: 30-33.

Reinares Lara, P., y Calvo Fernández, S. (1999), Gestión de la comunicación comercial, Madrid: McGraw Hill.

ReynotDs, J. (1992), «Generic Models of European Shopping Centre Develop. ment», Europeans Journal of Marketing, vol. 26, núm. 8/9: 49-61.

Rovira, A. (2000), I Congreso de Centros Históricos de la Comunidad Valenciana «Historia, Patrimonio y Arte», Libro de ponencias y comunicaciones, Valencia: ARCHIVAL, Asociación para la Recuperación de los Centros Históricos de la Comunidad Valenciana.

RovirA, A., y LLEÓ, G. (1999), El impacto de la actividad comercial en el territorio. Recomendaciones para su análisis. Estudios para el Plan de Acción Territorial aplicado a la distribución comercial, Valencia: Consejo de Cámaras de Comercio de la Comunidad Valenciana.

SAINZ dE VICUÑA ANCIN, J. M. (1996), La distribución comercial: opciones estratégicas, Madrid: ESIC.

- (1996), «Comercio tradicional. Opciones estratégicas», Distribución y Consumo, núm. 30 , octubre-noviembre.

- (2000), Marketing estratégico para el pequeño y mediano comercio, Valencia: PATECO, Consejo de Cámaras de Comercio de la Comunidad Valenciana, Conselleria de Industria y Comercio de la Generalitat Valenciana.

SANTESMASES, M. (1995), Marketing. Conceptos y Estrategias, 2. a ed., Madrid: Pirámide.

SerRA, E.; Español, J., y QuinTANA, M. (1996), El centro reinventat. Exploracions proyectuals per a un nou centre urbà, Barcelona: Fundació Politécnica de Catalunya, UPC.

TARRAGÓ, M. (1993), «Urbanismo comercial respuestas de futuro para el binomio comercio-ciudad», Distribución y Consumo, núm. 2, Mercasa.

- (1995), «Localización comercial e impactos territoriales», Distribución y Consumo, febrero-marzo: $30-38$

- (1999), Guia de redacción dels programes d'orientació per als equipaments comercials (POEC), Barcelona: Generalitat de Catalunya, Departament d'Industria, Comerç i Turisme.

VÁzQuEz, A. (2000), La imaginación estratégica. El caos como liberación, Barcelona: Granica. 